\title{
The effect of explicit teaching of apologies on Persian EFL learners' performance: When e-communication helps
}

\author{
Simin, Shahla $\bowtie$ \\ English Department, University of Isfahan, Iran (shahlasimin@yahoo.com) \\ Eslami, Zohreh Rasekh \\ English Department, Texas A\&M University, USA (zeslami@tamu.edu) \\ Eslami-Rasekh, Abbass \\ English Department, University of Isfahan, Iran (Abbasseslamirasekh@yahoo.com)
}

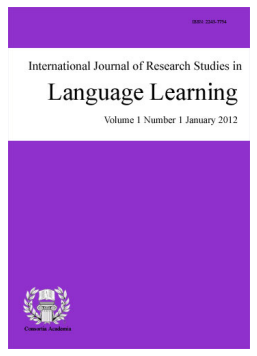

ISSN: $2243-7754$ Online ISSN: 2243-7762

OPEN ACCESS

Ketabi, Saeed

English Department, University of Isfahan, Iran (ketabi@fgn.ui.ac.ir)

\section{Abstract}

The present study was conducted to examine the effect of explicit teaching of the speech act of apology on learning and recognition of Persian EFL learners with the help of e-communication through exchange of e-mails. The participants of the study consisted of 60 upper-intermediate EFL learners majoring in English Literature and Translation who were divided into two groups: a) the explicit teaching group and b) the implicit teaching group. Accordingly, instruction on various apology situations was provided and the experimental group was asked to have e-communication through e-mail exchanges with their instructor during the semester. The study consisted of a pretest and a posttest which was considered to be quasi-experimental. The independent variable was the explicit teaching of speech acts and the dependent variable was learning success of the participants. After the treatment, the participants were given a posttest. The Analysis of the results revealed that the learners in the explicit teaching group who participated in e-mail exchanges gained significantly in terms of pragmatic proficiency required for strategies of apology. And the use of explicit teaching of apology involving them in e-communication exchanges significantly enhanced the pragmatic awareness of Persian EFL learners.

Keywords: apology speech act set; pragmatic competence; pragmatic instruction; raising pragmatic awareness; meta-pragmatic; explicit teaching; e-communication 


\section{The effect of explicit teaching of apologies on Persian EFL learners' performance: When e-communication helps}

\section{Introduction}

It is consensus that linguistic proficiency does not guarantee communicative efficiency. Since the introduction of communicative competence decades ago, applied linguists started focusing their research on appropriateness rather than considering formal questions of structure. Research has shown that cross-cultural clashes could be avoided by enhancing socio-pragmatic competence required in cross-linguistic communication contexts. Business, politics, translation, and effective cross cultural communication all depend on competence in how to use English appropriately in addition to grammatically. This fact highlights the significance of incorporating a pragmatic section to our EFL courses. Major problems that language learners face in intercultural communication are pragmatic which deals with use of language in an appropriate style. Therefore, for language learners, mastering the correct use of L2 speech acts is important in acquiring L2 pragmatic competence.

In order to communicate appropriately in a target language, pragmatic competence in second language (L2) should be reasonably well developed (Eslami, 2011). Since the early 1980s, researchers have established that foreign language learners' development of various aspects of pragmatic competence can be facilitated by the instruction of pragmatic routines and strategies in the foreign language classroom (Kasper \& Rose, 2001). Many studies have shown that pragmatic ability is teachable (Koike \& Pearson, 2005; Takahashi, 2001; Yoshimi, 2001); however, the question of how to teach pragmatic competence still remains, including the questions of both how and what to teach (Lingli \& Wannarruk, 2010).

Kasper (1997) and Kasper and Rose (2001) extensively discuss results of previous studies on pragmatic instruction and conclude that pragmatics can indeed be taught. Tateyama, Kasper, Mui, Tay, and Thananart (1997) examined the effects of instruction in pragmatics and demonstrated that Japanese pragmatic routine such as sumimasen, which is commonly used for getting attention, apologizing, and expressing gratitude, are teachable to beginning foreign language learners. Kondo (2001) administered Oral Discourse Completion Tasks both before (pre-test) and after (post-test) explicit pragmatic instruction and concluded that instructional effects could be significant.

Awareness-raising (Rose, 1994) is one method of pragmatic teaching strategies. Active video-viewing activities employed for the purpose the effect of which showed that an approach using pragmatic consciousness-raising could have the distinct advantage of providing learners with a solid foundation in pragmatic awareness. Bardovi-Harlig (1996) in her endeavor to bring pragmatics and pedagogy together, demonstrated the results of helping learners increase their pragmatic awareness in a teacher centered classroom where the teachers tell and the learners receive the information.

According to Eslami-Rasekh (2005), through awareness-raising activities, students acquire information about pragmatic aspects of speech. The question is: what strategies are used for apologizing in their L1 in contrast with L2. What is considered an offence in the source culture compared to the target culture, what degrees of offence exist in variable contextual situations, and how is the nature of the relationship between the participants affects the use of apologies.

The aim of pragmatic teaching is mainly to expose learners to the pragmatic aspects of languages in contrast and provision of analytical tools needed to arrive at generalizations concerning contextually appropriate speech. These activities are designed to make learners consciously aware of cross-cultural differences between the native and target language speech (Schmidt 1993).

Even though empirical studies have indicated that positive impact of pragmatics instruction on second- or 
foreign- language learners, few studies have examined the implementation of pragmatics instruction using computer-mediated communication (CMC) aiming to enhance students' skill in employing proper strategies of politeness (Eslami \& Liu, 2013). In an Iranian context, research works have been conducted on varying aspects of speech including the norms of apology; however, what makes this work novel lies in the fact that CMC is a new media getting popularity among students. The thing is that motivation which is the central condition for learning EFL is increased due to the fact that EFL students find it necessary to have the communicative skill for using the media and essentially e-communication. Their need for the media is a decisive encouraging motivational tool which forces them to try to learn what is appropriate to say and how speech acts are performed in appropriate styles.

The novelty of this study, in addition to choosing the CMC as the media of study, is in the fact that empirical rather than mere judgmental data have been collected for analysis; and the fact that explicit instruction in an Iranian context in a design of study applied in this study makes the effort useful. Consistent with this line of research, the study intends to investigate the role of instruction in pragmatic awareness and pragmatic instructional effect on EFL learners' skill in using appropriate strategies of apology in EFL in their discourses through such CMC media as e-communication. Since speech act of apology varies across various socio-cultural systems and it is one of the most frequently used speech act in our daily communication and also a fundamental one which is a part of human communication to maintain good relations between interlocutors (Brown \& Levinson, 1987). The present study is an attempt in the direction of tapping pragmatic knowledge of Iranian EFL learners and substantiating the effectiveness of instruction in pragmatics by using CMC interactions with EFL instructors.

\section{Background}

The significance of pragmatics has been stressed in the domain of language learning from 1980s. Pragmatics is the study of how people comprehend and produce a communicative act or speech act in a speech situation. Like other speech acts, apology has attracted the attention of many researchers, especially those interested in foreign language teaching and learning.

Cohen (1999) stated that the word apology is derived from the Greek root logos, meaning speech or word. Though originally associated with a formal justification apology also refers to remarks made following an injury, whether intentional or unintentional. In this respect, an apology is defined as, an honest and open acknowledgment of the offense with expression of regret for it, by the way of reparation. Brown and Levinson (1987) refer to apology as intrinsically a negative politeness strategy, which indicates Speaker's (S) reluctance to impinge on its negative face, Hearer's $(H)$ want that his actions be impeded by others. From S's perspective, apologies are Face threatening act (FTA), which imply damage to S's positive face (Brown \& Levinson, 1987).

In Brown and Levinson's terms (1978), apologies are politeness devices expressing attention to the hearer's face needs in context of an offense. Olshtain (1989) attempts to incorporate these aspects, defining apology as a speech act which is intended to provide support for the $\mathrm{H}$ who was actually or potentially malaffected by violation $\mathrm{X}$. Hence the act of apologizing is face saving for the $\mathrm{H}$ and face-threatening for the $\mathrm{S}$ (Brown \& Levinson, 1987). Apologies fall under expressive speech acts, according to Searle's (1969) taxonomy, performed to indicate the psychological emotions of the speakers. As Fahmi and Fahmi (2006) states, in order for an apology to have an effect, it should reflect true feelings. One cannot effectively apologize to another and truly reach him/her unless one portrays honest feelings of sorrow and regret for whatever one has done. Lakoff (1977) notes that politeness and apologies are devices employed by interactants to help reduce friction in interpersonal communication. Thus, apologies provide a remedy for an offense and help restore harmony as well as social equilibrium (Holmes, 1995; Edmondson, 1981; Leech, 1983).

In addition to definitions provided in the literature for apology, there are components which make up apology as a speech act set. According to Blum-Kulka, House, and Kasper (1989) an apology can be realized 
through three main components namely Alerters, Head acts, and Adjuncts. Alerters function as an initiator to alert the addressee's attention. A head act is the minimal unit through which the main apology is realized and can be also intensified. Adjuncts which follow the main apology strategy are what called by Blum-Kulka, House, and Kasper (1989) as Supportive moves. Supportive moves are realized when the speakers opt for strengthening the apology strategy in order to make it more appropriate with regard to the severity of the offense committed and with regard to power and distance relations between the interlocutors engaged in a situation. An example of apology speech act set is as following:

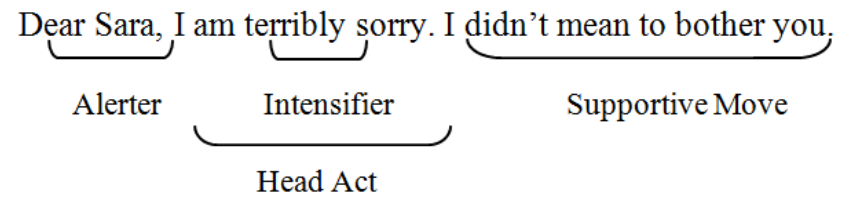

To offer an apology one needs to use one or a combination of apology strategies in order to be impressive in a remedial exchange. The strategies are the plans designed for a particular purpose. Brown (1987) states that apologetic strategies are specific methods of approaching an offence, modes of operation for confirming an assuring of mutual solidarity and planned designs for controlling and manipulating certain speech acts. People act differently in the choice of strategies for apology instances. One person may prefer the strategy of expressing an explicit apology whereas another person may only use an explanation as a strategy to indirectly apologize. Therefore, circumstances and personal choice lead to the use of different strategies to remedy an offensive action.

One of the most influential views on the classification of apologies is Goffman's (1971). Goffman distinguishes two types of compensations: ritual and substantive. Following this distinction, Fraser (1981) provides two motivations associated with substantive and ritualistic apologies; in substantive apology the speaker wants to remedy the damage or harm caused by the offense while the ritual apology may be produced as a kind of habit associated with certain routines or when the respondent is not responsible for the offense. Fraser (1980) classified apologies into two main groups: direct and indirect apologies. He subdivided the direct apology strategies as announcement of apology, stating the obligation to apologize, an offer for apologizing and request for apology acceptance. And for indirect, he suggested five strategies: expressing regret, requesting forgiveness, acknowledging responsibility, promising forbearance, and offering redress. Olshtain and Cohen (1983) suggested that apologies can be realized as a speech act set including an illocutionary force indicating device (IFID), an expression of the speaker's responsibility for the offense, an explanation or account of the situation or of the cause which gave rise to the violation, an offer of repair, and a promise of forbearance. Blum-Kulka and Olshtain (1984) provide five verbs (regret, excuse, be sorry, forgive, pardon) beside (apologize) as performative verbs in English and hence IFID. Bergman and Kasper (1993) used another model to analyze their data: IFID, downgrading (reducing the severity of offense, and reducing responsibility - including excuse and justification, claiming ignorance and denial); upgrading by use of adverbial (i.e. intensifying of IFID); taking on responsibility or admitting the offense (including self-blame, lack of intent and admission of face); offer of repair; and verbal redress (concern for the hearer and promise of forbearance).

\subsection{The Role of Instruction on Pragmatics}

"Despite the growing body of evidence that supports the role of raising pragmatic awareness for language learners, L2 instruction mainly focuses on grammar and ignores the pragmatic development of language learners" (Eslami, 2011, p. 2). Studies addressing the realization of speech acts by second- or foreign-language learners (Bardovi-Harlig, 2001; Bardovi-Harlig \& Hartford, 1996; Olshtain \& Blum-Kulka, 1985) have found that even advanced language learners who know grammar and word meanings still often face difficulties in comprehending a speaker's intention or conveying appropriate politeness in communicative contexts. Studies have found that when pragmatics is not offered, opportunities for developing pragmatic competence are quite limited (Kasper, 2000). According to the research, without explicit attention to pragmatics, its development by 
The effect of explicit teaching of apologies on Persian EFL learners' performance: When e-communication helps

learners can take a considerable amount of time (Cohen, 2008; Rose, 2005).

Many studies have examined the effect of instructional intervention in the development of pragmatic knowledge (e.g., Elami \& Liu, 2013; Eslami-Rasekh, 2005; Cohen, 2005; Schauer, 2006). Most of these studies found a positive impact on language learners' pragmatic knowledge, which supports the hypothesis that pragmatic ability can be enhanced or developed through systematic planned classroom activities.

Following Eslami and Liu (2013), Cohen (2005), Kasper and Schmidt (1996) and Bardovi-Harlig (1999), who pointed out the necessity of conducting research about the role of instruction in pragmatics development in order to make stronger the link between pragmatic competence and foreign language learning, the researcher of this study aims to carry out a study on raising pragmatic awareness by the help of explicit instruction on Iranian EFL learners.

\title{
2.2 Computer-Mediated Communication
}

Computer-mediated Communication (CMC) has been rapidly replacing other means of communication in many institutions of modern life, including universities, and e-mail is one of the most commonly used forms of it (Bulut \& Rabab'ah, 2007). Baron (1998) sees e-mail as "an ideal tool for building and maintaining social relationships" (p. 155). In the university context, the nature, goal and frequency of it may depend on various factors such as the teaching traditions, technological facilities and specific-course requirements. Even though there still might be institutions in some countries where students and teachers have limited technological facilities and access to internet $(\mathrm{Gu}, 2004)$, using e-mail as a means to interact with faculty has increased greatly in others. As a result,

\begin{abstract}
"Different email interactions have emerged in the daily life of people. For instance, student-student, student-teacher, student-parent, employee-employer, customer-company, teacher-teacher, and doctor-patient are among the most common email interactions in everyday life. Among different groups of people, university students, in particular, use internet more than others" (Akkaya, 2007, p. 2).
\end{abstract}

E-mail is becoming a widely and frequently used communication medium between university students and their professors and is replacing the traditional face-to-face office hours. Studies investigating the communication purposes for which students use email with their professors have found similar facilitative and academic functions: building a relationship, getting information/advice about course materials and quizzes, addressing late work and missed classes, challenging grades, showing interest in and understanding of course material, and get[ting] on the instructor's good side (Martin, Myers, \& Mottet, 1999; Collins, 1998; Marbach-Ad \& Sokolove, 2001; Payne, 1997; Poling, 1994). At a university context, communicating with the faculty via e-mail may be more advantageous as students will have "more control over planning, composing, editing, and delivering messages than face-to-face communication" (Duthler, 2006, p. 501).

In this regard, researchers have examined the use of various forms of computer technologies for promoting L2 pragmatic development. Studies have found several advantages for teaching pragmatics through computer technologies. Computer platform permits the teaching features of pragmatics that are not easily incorporated in traditional settings and provides an authentic learning environment where learners engage in real-life communication $(\mathrm{Li}, 2012)$. However, there is still a relative gap in the use of technology and computer mediated communication in promoting the EFL learners pragmatic competence (Eslami \& Liu, 2013). In an effort to fill this gap, the present study integrated technology to pragmatic instruction to EFL leaners to compare the different teaching effect of explicit and implicit instruction using CMC on learning of apology speech act of Persian EFL learners and to investigate the magnitude of the effect. To do so, in both groups, e-communication was encouraged and it used as facilitator in this research. 


\section{Method}

\subsection{Participants}

The participants of the study consisted of 60 homogenized upper-intermediate EFL learners majoring in English Literature and Translation, who were randomly divided into two groups: a) the explicit teaching group and b) the implicit teaching group. They were registered for letter writing course in which they need to write mostly e-mailed letters with varying illocutionary forces included the speech act of apology among various other functions: greetings, thanking, apologizing, applications, inquiries, congratulating. Accordingly, instruction on various situations needing apology was provided during the semester through e-communication. The explicit group was also to have e-communication with their instructor over the semester and send their homework via e-mails and instead of face-to-face communication they were encouraged to use e-mail as their means of communication. The selection of upper-intermediate students as participants was helpful for the goal of our research which was collecting a corpus of e-mailed data dealing with the speech act in question. The participants had taken TOEFL placement test at the beginning of the semester and the means of the two groups revealed that both groups were homogenous in terms of language proficiency. The age range was from 20 to 27 , and they were both male and female students.

\subsection{Instruments and materials}

The research was designed to involve a pretest and a posttest which was considered to be quasi-experimental. The independent variable was explicit teaching of speech acts and the dependent variable was learning success of the participants. Six types of materials and instruments were used in this study to provide the researchers with the required data: 1) a version of TOEFL test (Longman TOEFL, tenth edition, 2000); 2) a questionnaire for diagnostic assessment (a collection of different apologetic situations in a mode of random order based on Olshtain and Cohen's (1983) study); 3) Pretest and posttest, 4) E-mail exchanges between students and their instructor, 5) Various hypothetical apology situations in which students were asked to write letters/e-mails and apologize (e.g. missing an appointment, wrong behavior in the class, delay in submitting homework, coming late to the class, missing sessions of the course, and many others; and 6) Learners' feedback and discussion on each situation (e.g. how to apologize).

For the explicit instruction group (EIG), an explicit instruction method was used while for the implicit instruction group (IIG) an implicit instruction method was adopted. The instructor was the same person for both groups and the instruction duration lasted for a semester, about 4 months. The steps in instruction were similar to those used for the EIG, except that no explicit information and feedback was provided for IIG. Such explicit instruction and feedback helped learners become sensitive to social and pragmatic factors that affect speech acts. Some part of the class was devoted to the distinction between "I' $m$ sorry" and "Excuse me" or other appropriate choices of a strategy or any other elements of the apology act. By this way, students realized that the speech act can be realized in different ways, and they do have certain preference in the way it is conducted.

In each hypothetical apology situation, the learners were asked to talk to their partners first, discuss what happened, then write an apology letter accordingly. The letters were given to instructor and the next session the instructor gave the revised letters back to learners, provided corrective feedback on the use of target items and the production of apology strategies. In fact, the instructor provided feedback explicitly on any inappropriate use. The instructor also talked about each different apology strategy the learners used, and samples of authentic apology letters from the textbooks and dictionaries were distributed, they would read, discussed and learned their mistakes or inappropriate strategies they had used. Also the instructor offered an explicit use in apology strategies whenever the learners needed. In addition, some socio-cultural issues were taught by the instructor and also the examples were provided by the instructor.

One of the important stages of the instruction was when the instructor explained the function and 
appropriate use of apology strategies and led a discussion and comparison of Persian and English apology strategies. While in the IIG, the focus was on forms, i.e. the instructor would provide no comments on the learners' discussion on usage of apology strategies. In contrast, in EIG, corrective feedback was provided: the instructor provided feedback on the production of apology speech act and commented on strategies and explicitly corrected any inappropriate use whereas, in the IIG, implicit feedback was provided. The learners were informed of whether the strategies they used were correct or incorrect and no explicit instruction on function and use of such strategies.

In EIG, Learners were presented with various ways of performing apologies in English compared to those of Persian. These Considerations helped the learners to distinguish their pragmatic transfer from their native language. For example, they found that the strong Persian preferences for the apology strategy may be reflected in their English apologies as well. They also realized that they sometimes cannot do what they can in their native language when they use English because of their linguistic limitations. In this regard, some students expressed that they were not comfortable to use some strategies because of their cultural values. Therefore, such discussion with the instructor and their classmates successfully helped learners to raise their pragmatic awareness.

Then for the other session they were asked to study more samples by searching on the net, rewrite their letters according to the instructor feedback and email their homework to their instructor. In doing so, if they missed any session or did not deliver the homework on time, they would send apology emails to their instructor. Even later, they sent apology emails for misbehavior in the class, speaking loudly with their instructor, having their cell-phone rung during the class, coming to the class late, etc. that means they learned when and how to use apology act and they preferred e-communication instead of face-to-face communication. Since their e-mails could have an impact on their academic achievement and letter writing course scores, they were very careful on writing apology e-mails and they used more than one apology strategy. They usually began with apology expressions and then they gave explanation of the situation in which the offense was committed and mostly end with a request for forgiveness or promise for compensation. The following e-mail is an example of apology letters which was sent to the instructor:

\section{Dear Teacher,}

I'm so sorry for missing the class on Saturday. I was at the exam and after

I had a problem so that is the reason I missed it. Please forgive this one.

Thanks.

Have a good time.

The EIG group first was asked to write the letter (e.g. apology letter for a hypothetical situation) then they received the corrective feedback and were exposed to several samples on variety of situations needing apology, and in the final stage they could practice what they have been taught through e-communication with their instructor. As it can be seen students- teacher interaction via e-mail was not obligatory, they could do it face-to-face instead but over the semester they preferred to perform such interaction via e-mail, they were motivated to do such and this interaction was helping them to practice what they have learned in real life situations. In EIG group, after the students sent e-mail to their instructor, their e-mails were corrected and they would receive both the corrective feedback and teacher's reply to that e-mail via e-communication. But in IIG group the students didn't have such chance to get the corrective feedback via e-mail and they just received the reply of the instructor to their e-mail. Therefore, the IIG group had the chance to have e-communication with their instructor but they would not get aware of their mistakes.

\subsection{Data Collection and Analysis Procedures}

The present study used a quasi- experimental design. The two experimental groups were taught with two teaching methods, one group was taught explicitly while the other group received no explicit instruction. Both groups had e-communication with the instructor while the implicit instruction group did not get corrective feedback of the emails they sent. They were upper-intermediate EFL learners majoring in English literature and 
Simin, S., Eslami, Z. R. ., Eslami-Rasekh, A., \& Ketabi, S.

translation which were tested with a pretest and posttest. The pretest aimed to examine the participants' knowledge of English apologies before the treatment- at the beginning of the semester. At the end of the coursewhen the academic semester was done, the written Discourse Completion Test (DCT) as the posttest was administered. The duration between the two tests was a semester- 4 months. The pretest and posttest used the same written DCT test so as to compare the results of the tests. After administrating the pretest and posttest, a comparison of the pretest scores of the two groups was made. It was assumed that the scores of the participants in the EIG and IIG had no difference in the pretest. According to the t-test, the mean scores for the written DCT pretest were not significantly different. Also the mean scores of the two groups were almost the same.

\section{Results}

The study employed a pretest-posttest group design. Descriptive statistics were first computed to explore the data. A comparison between explicit instruction group (EIG) and implicit instruction group (IIG) was made in terms of mean scores of the written posttest DCT. Then, a t-test was carried out to compare the group means. The results are presented in the following sections.

\subsection{A Comparison of the Pretest and Posttest Results}

Participants' scores on the pretest - After assigning the participants into two groups a pretest were administered. To carry out the statistical analysis of this test first of all, the scores of the different apology situations on the questionnaire for the two groups were computed and the means of the two groups were compared. A comparison of the pretest (the questionnaire of different apology situations) means revealed no significant difference between the two groups on the 15 multiple choice test questions. The means and standard deviation of the two groups are presented in Table 1.

\section{Table 1}

The result of $t$-test for pretest

\begin{tabular}{|c|c|c|c|c|c|c|c|}
\hline \multicolumn{6}{|c|}{ Groups } & \multirow[b]{3}{*}{$t$} & \multirow[b]{3}{*}{$d f$} \\
\hline \multicolumn{3}{|c|}{ Implicit } & \multicolumn{3}{|c|}{ Explicit } & & \\
\hline$M$ & $S D$ & $n$ & $M$ & $S D$ & $n$ & & \\
\hline 11.1333 & 3.00268 & 30 & 12.0000 & 3.74166 & 30 & -0.989 & 58 \\
\hline
\end{tabular}

As Table 1 indicates, the observed $t$ value is -.989 with the level of significance of 0.327 and degree of freedom of 58, which means there is no meaningful difference between the two groups of explicit teaching group and the implicit one.

Participants' scores on the posttest - The aim of this study was to find out whether explicit apologetic speech act teaching strategies and e-communication between instructor and learners has any significant influence on the performance of the students and if yes, to understand if EFL students' learning of apology speech act corresponds to the standard style of apologizing. Accordingly, the two groups of explicit (EIG) and implicit (IIG) after undergoing the treatment took a posttest (15 apology situations based on Olshtain and Cohen (1983) on a multiple choice questionnaire), Table 2 presents the results.

Table 2

The result of $t$-test for posttest

\begin{tabular}{|c|c|c|c|c|c|c|c|}
\hline \multicolumn{6}{|c|}{ Groups } & \multirow[b]{3}{*}{$t$} & \multirow[b]{3}{*}{$d f$} \\
\hline \multicolumn{3}{|c|}{ Implicit } & \multicolumn{3}{|c|}{ Explicit } & & \\
\hline$M$ & $S D$ & $n$ & $M$ & $S D$ & $n$ & & \\
\hline 13.1667 & 2.35010 & 30 & 17.1667 & 1.36668 & 30 & -8.059 & 58 \\
\hline
\end{tabular}

As shown in Table 2, the means of the two groups are different. In order to understand whether or not these 
The effect of explicit teaching of apologies on Persian EFL learners' performance: When e-communication helps differences are statistically significant, a t-test was employed. Table 3 reveals the results of this t-test.

Table 3

Results of t-test for pretest and posttest for EIG and IIG

\begin{tabular}{|c|c|c|c|c|c|c|c|}
\hline \multicolumn{6}{|c|}{ Groups } & \multirow[b]{3}{*}{$t$} & \multirow[b]{3}{*}{$d f$} \\
\hline \multicolumn{3}{|c|}{ Implicit } & \multicolumn{3}{|c|}{ Explicit } & & \\
\hline$M$ & $S D$ & $n$ & $M$ & $S D$ & $n$ & & \\
\hline 2.0333 & 3.73689 & 30 & 5.1667 & 4.30784 & 30 & -3.009 & 58 \\
\hline
\end{tabular}

Table 3 shows that the mean scores of the EIG and IIG was significantly different. As it can be seen in the above table, the mean score for the experimental group is high enough to claim that explicit teaching of speech act apology has a significant influence on the learners' performance and recognition of the strategies use in apologizing. The analysis of the results also indicates that the participants in the explicit teaching group gained significantly in terms of language proficiency with regard to apology speech act and recognition of appropriate apologizing. To compare improvement of both groups after instruction, the mean of the scores was calculated. Table 3 shows the results of difference between pretest and posttest in both groups. In Implicit instruction group (IIG) the mean score of improvement after implicit instruction is 2.03 and for explicit instruction group (EIG) is 5.17. As Table 3 indicates, there is a statistically meaningful difference between the two groups after instruction.

As illustrated in Table 3, the observed t value is -3.009 with the level of significance of 0.004 and degree of freedom of 58, which means there is significant meaningful difference between the two groups after instruction. Figure 1 depicts the graphical representation of the results of pretest and posttest between the two groups.

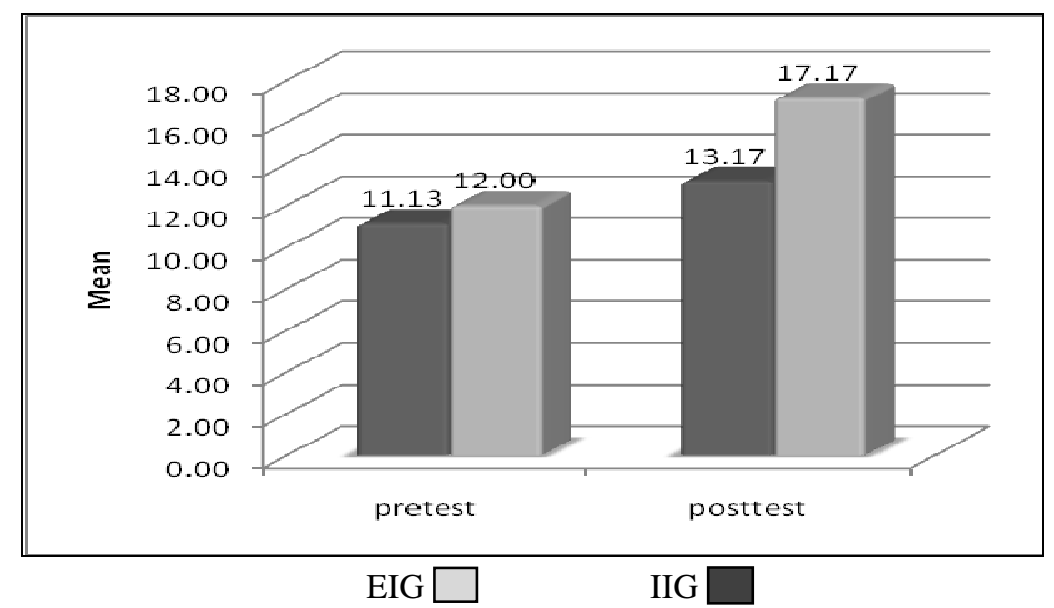

Figure 1. Graphical Representation of the pretest and posttest

As shown in Figures 2 and 3, there is a drastic change in the scores of EIG from pretest to posttest, but slight changes can be seen in IIG.

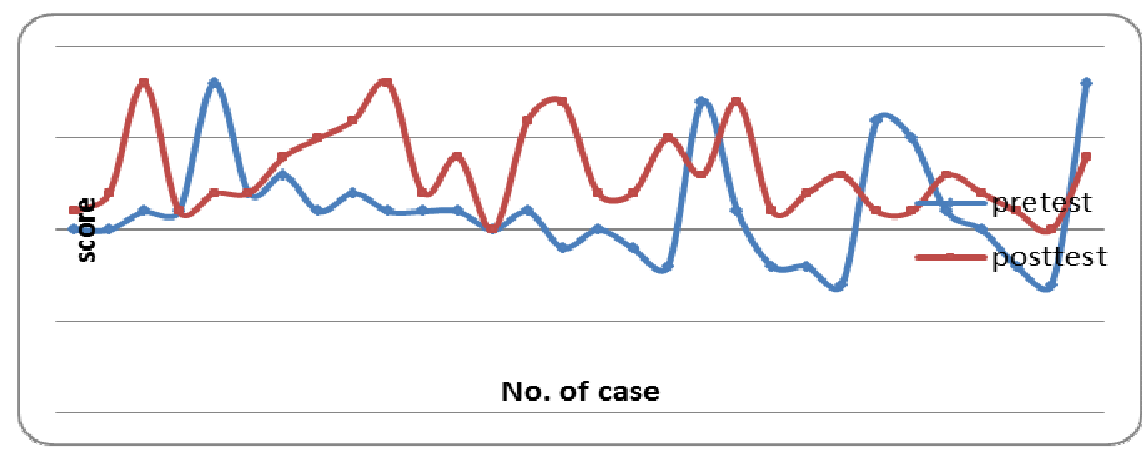

Figure 2. Scores on pretest and posttest in implicit group 


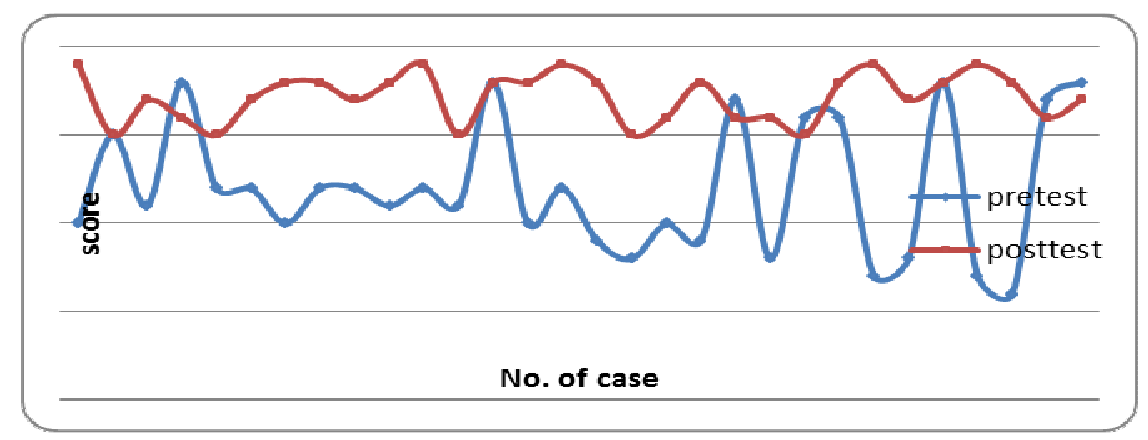

Figure 3. Scores on pretest and posttest in explicit group

According to a qualitative analysis of the written DCT between EIG and IIG in the posttest, results support the quantitative data, because the explicit teaching in teaching apologies was better than the implicit teaching. The EIG could use appropriate apology strategies and a combination of these strategies to apologize appropriately and effectively. The analysis indicates that the EIG achieved better results than the IIG in using apologies. It seems that e-communication between the instructor and learners and receiving corrective feedback on the e-mails had a meaningful influence on learning speech act of apology.

\section{Discussion and Conclusion}

In this study, it was aimed to investigate the effect of explicit teaching of apology speech act on Iranian EFL learner's language proficiency and learning. To attain this end a TOEFL test was applied to eliminate the pre-existing differences and to make subjects homogeneous. Two separate t-tests were applied to the means of both groups: the pretest showed no significant difference between the two groups. But the amount of t-observed in the post-test is high enough to claim that explicit teaching of apology speech act with the help of e-communication has a significant effect on the learner's awareness on recognition and production of speech act of apology. As the data showed the EIG outperformed the IIG. In general, the explicit instruction and e-communication was salient and targeted at what the learners needed. As stated in Cohen (2008) and Cohen and Shively (2007), strategy instruction can be an important component in pragmatics instruction, because such instruction is salient and explicit.

From the perspective of the noticing hypothesis (Schmidt, 1993), this improvement may be due to the degree of noticing. The teacher's explicit explanation, explicit feedback and exchange of e-mails in real life situation could enhance the students' awareness. In contrast, implicit comparison or feedback might mislead the learners so their noticing was not very concentrated. As it was seen in data, implicit teaching group lacked sensitivity to certain distinctions that standard English or natives made, e.g., between forms for realizing the strategy of expressing apology such as "excuse me", "pardon me", "sorry" and "forgive me". Also they tended to use "excuse me" more often and sometimes in contexts where this realization was not appropriate. In fact, a high degree of noticing can be effective in teaching pragmatic competence. As previous studies have showed higher levels of awareness are associated with more explicit conditions and learners with greater awareness have an increased ability to recognize and produce target forms than those with less awareness (Leow, 2000).

Furthermore, corrective feedback in the course of explicit instruction can enhance the degree of noticing. For the explicit instruction, the correction was direct and obvious; for the implicit instruction the feedback was implicit. As Yoshimi (2001) notes, communicative practice and corrective feedback may enhance the noticing afforded by explicit instruction. In this study, e-communication was a help besides those explicit instruction and corrective feedback; via exchange of e-mails learners consciously wrote e-mails to their instructors in real life situations and it helped the level of noticing. Learners would learn better in real life situations and when they understand they can use what they have learned already it will create more desire and motivate them to learn in more effective way. Therefore, the explicit teaching along with the e-communication lead to noticing and 
learners could have the awareness to notice the different forms and functions and as a result, the use of correct expression of the EIG was much greater than that of the IIG. One possible reason was that apology act and its strategies as well as use of correct expression and receiving e-communication feedback were the focus of their learning. In fact, instruction in pragmatics helped learners realize and discover common and different aspects of conducting speech acts across cultures.

In this study, the use of explicit teaching of apology speech act assures that explicit teaching of pragmatic aspects of apology can be adopted by using different tasks. Therefore, the experimental treatment in which explicit instruction of apology speech act involved the activities used in sessions revealed significant effect on the learning of apologetic semantic formulas. It can be concluded that explicit instruction is better than implicit instruction for teaching English apology strategies. Also due to the salient features in the explicit instruction, the performances in correct use of apology act and strategy choices in the EIG were better than those in the IIG. One reason can be of heavy influence of L1 and Persian culture and inadequate presentation of English apologetic speech act in implicit instruction, strategy choices and appropriate production were not good enough in IIG. Instruction is effective in terms of boosting the pragmatic knowledge of students. So attempts must be made to include instruction in the curriculum of our universities. As for pedagogical implications, when teaching English speech acts to EFL learners, English culture and learners' native culture need to be included in instruction so as to give the learners a very clear picture of the differences between the two cultures (Lingli \& Wannaruk, 2010).

To put in a nutshell, by explicit instruction and raising awareness, misunderstandings which were caused by differences in performing speech acts between Persian and English which was one of the reasons of failure in communication could be solved. This kind of explicit instruction and involving learners in different tasks and real life situation (i.e. e-communication) made learners aware of what they already knew and encourage them to use their universal or transferable Persian pragmatic knowledge in English contexts. And finally, learners realized appropriate linguistics forms and strategies they are likely to be encountered in performing speech act of apology in their real life situation. The results of this study support the need for instruction of e-mail pragmatics to second language learners and reveal the possible benefits of such instruction.

\subsection{Implications}

In essence, programs of EFL aim to promote communication skills of EFL learners. The practicality of instruction lies in the ability of the students to communicate appropriately across the two cultures. It has been discovered that linguistic proficiency does not guarantee communicative skill which is vital for successful cross-cultural communication. The EFL instructional programs with this goal have the advantage of enabling the prospectus students to do their work in fields involving cross-cultural understanding. Mis-interpretation could cause conflict and hence be regarded as an unfavorable consequence of not knowing the norms of being polite. The students who aim to choose jobs in fields dealing with cross-cultural communication activities involving potentially face threatening speech acts may jeopardize their mission by inappropriately conveying the illocutions of their speech. One consequence could be the misunderstanding caused as a result of unintended outcome of what is said and how one speaks. The findings with this nature are required to be applied in our EFL textbooks to avoid, as much as possible, the false messages which might be conveyed by a non-native speaker of English; one whose job is important and can jeopardize a mission in politics, business, or in other fields of activity. Even in everyday life situations it is vital to be able to send emails which are appropriate given the accepted social norms.

Nowadays, online education has been growing in popularity in higher education (Harmon \& Jones, 1999), therefore, appropriate e-mail exchanges are the essence of such education. In fact,

“... online technology provides various interactive strategies for active learning. Online learning will continue to grow in importance for learners. The challenge for educators is to learn how to provide a positive social environment using an electronic medium. Instructional programs will 
Simin, S., Eslami, Z. R. ., Eslami-Rasekh, A., \& Ketabi, S.

continue to change as new technologies grow. Instructors therefore will need to adapt, change, and continue to learn about how this electronic environment can be used to foster a social atmosphere, and they will need to recognize their role as change agents” (Khanal, 2013, p. 99).

\section{References:}

Akkaya, A. (2007). Student-teacher e-mail interaction: Pragmatic markers of gender, nationality and status of the students. Unpublished Masteral thesis, Southern Illinois University, Carbondale.

Bardovi-Harlig, K. (1996). Pragmatics and language teaching: Bringing pragmatics and pedagogy together. In L. F. Bouton (Ed.), Pragmatics and language learning, (Vol. 7, pp. 21-39). University of Illinois, Urbana-Champaign: Division of English as an International Language.

Bardovi-Harlig, K. (1999). Exploring the interlanguage of interlanguage pragmatics: A research agenda for acquistional pragmatics. Language Learning, 49(4), 677-713. http://dx.doi.org/10.1111/0023-8333.00105

Bardovi-Harlig, K. (2001). Evaluating the empirical evidence: Grounds for instruction in pragmatics? In G. Kasper. \& K, Rose (Eds.), Pragmatics and language teaching (pp. 11-32). Cambridge: Cambridge University Press.

Bardovi-Harlig, K., \& Hartford, B. S. (1996). Input in an institutional setting. Studies in Second Language Acquisition, 18, 171-188. http://dx.doi.org/10.1017/S027226310001487X

Baron, N. (1998). Letters by phone or speech by other means: The linguistics of email. Language and Communication, 18, 133-170. http://dx.doi.org/10.1016/S0271-5309(98)00005-6

Bergman, L. M. \& Kasper, G. (1993). Perception and performance in native and nonnative apology. In G. Kasper \& S. Blum-Kulka (Eds.). Interlanguage Pragmatics. (pp. 82-107) Oxford: Oxford University Press.

Blum-Kulka, S., \& Olshtain, E. (1984). Requests and apologies: A cross cultural study of speech act realization patterns. Applied Linguistics, 5, 196-213. http://dx.doi.org/10.1093/applin/5.3.196

Blum-Kulka, S., House, J., \& Kasper, G. (Eds.). (1989). Cross-cultural pragmatics: Requests and apologies. Norwood, New Jersey: Ablex.

Brwon, P., \& Levinson, B. (1987). Politeness: Some universals in language usage. London: Cambridge University Press.

Bulut, D., \& Rabab'ah, G. (2007). Pragmatics of e-mail communication between Saudi female students and male professors. The IALT CALL Journal, 3(3), 49-73.

Cohen, A. D. (2005). Strategies for learning and performing L2 speech act. Intercultural Pragmatics, 2(3), 275-301. http://dx.doi.org/10.1515/iprg.2005.2.3.275

Cohen, A. D. (2008). The teaching of pragmatics in the EFL classroom. ILI Language Teaching Journal, 3(2), $1-28$.

Cohen, A. D., \& Shively, R. L. (2007). Acquisition of requests and apologies in Spanish and French: Impact of study abroad and strategy-building intervention. The Modern Language Journal, 91(2), 189-212. http://dx.doi.org/10.1111/j.1540-4781.2007.00540.x

Cohen, J. R. (1999). Advising clients to apologize. Southern California Law Review, 72, 1009-1069.

Collins, M. (1998). The use of e-mail and electronic bulletin boards in college-level biology. Journal of Computers in Mathematics and Science Teaching, 17(1), 75-94.

Duthler, K. W. (2006). The politeness requests made via email and voicemail: Support for the hyperpersonal model. Journal of Computer-Mediated Communication, 11(2), 500-521. http://dx.doi.org/10.1111/j.1083-6101.2006.00024.x

Edmondson, W. J. (1981). “On Saying you are sorry.” In F. Coulmas (Ed.). Conversational routine. The Hague: Mouton.

Eslami, Z. R. (2011). In their own voices: Reflections of native and nonnative English speaking TESOL graduate students on on-line pragmatic instruction to EFL learners. Electronic Journal for Teaching English as a Second or Foreign Language, 15(2), 1-21.

Eslami, Z. R., \& Liu, C. H. (2013). Learning pragmatics through computer-mediated communication in Taiwan. 
The effect of explicit teaching of apologies on Persian EFL learners' performance: When e-communication helps

Iranian Journal of Society, Culture, \& Language, 1(1), 52-73.

Eslami-Rasekh, Z. (2005). Raising the pragmatic awareness of language learners. English Language Teaching Journal, 59(2), 199-208. http://dx.doi.org/10.1093/elt/cci039

Fahmi, R., \& Fahmi, R. (2006). Apology strategies of Jordanian EFL university students. Journal of Pragmatics, 38, 1901-1927. http://dx.doi.org/10.1016/j.pragma.2005.11.004

Fraser, B. (1980). "On apologizing”. In F. Coulmas (Ed.). Conversational routine. The Hague: Mouton.

Fraser, B. (1981). On apologizing. In F. Coulmas (Ed.). Conversation routine: Exploration in standardize communication situations and pre-patterned speech (pp. 259-71). The Hague: Mouton.

Goffman, E. (1971). Relations in public: Microstudies of the public order. Harmondsworth: Penguin.

Gu, P. (2004). Leaving the bathtub to make waves. Essential Teacher, 1(4), 32-35.

Harmon, S. W., \& Jones, M. C. (1999). The five levels of Web use in education: Factors to consider in planning online courses. Educational Technology, 39(6), 28-31.

Holmes, J. (1995). Sex differences and apologies: One aspect of communicative competence. In H.D. Brown \& S. Gonzo (Eds.), Readings on Second Language Acquisition (pp. 362-385). Englewood Cliffs, NJ: Prentice Hall Regents.

Kasper, G. (1997). Can pragmatic competence be taught? Honolulu, HI: University of Hawai'i at Manoa, Second language teaching and curriculum center. Retrieved October 14, 2007 from http://www.lll.hawaii.edu/nflrc/NetWorks/NW6/

Kasper, G. (2000). Pragmatics in EFL Contexts [Electronic Version]. Retrieved 13 February 2008, from http://www.jaltpublications.org/tlt/articles/2000/07/kasper.

Kasper, G., \& Rose, K. R. (2001). Pragmatics in language teaching. Cambridge: Cambridge University Press.

Kasper, G., \& Schmidt, R. (1996). Developmental issues in interlanguage pragmatics. Studies in Second Language Acquisition, 18, 149-169. http://dx.doi.org/10.1017/S0272263100014868

Khanal, P. (2013). Making virtual learning interactive and meaningful: Implications of constructivism for adult learners. International Journal of Research Studies in Education, 3(1), 91-102.

Koike, D. A., \& Pearson, L. (2005). The Effect of instruction and feedback in the development of pragmatic competence. System, 33, 481-501. http://dx.doi.org/10.1016/j.system.2005.06.008

Kondo, S. (2001). Instructional effects on pragmatic development: Refusal by Japanese EFL learners. Publications of Akenohoshi Women's Junior College, 19, 33-51.

Lakoff, R. (1977). What you can do with words: Politeness, pragmatics and performatives. In A. B. Rogers \& J. Morphy (Eds.), Proceeding of the Texas Conference on performatives, presuppositions and implicature. (pp. 79-105). Arlington: Center for Applied Linguistics.

Leech, G. (1983). Principles of pragmatics. New York: Longman.

Leow, R. (2000). A study of the role of awareness in foreign language behavior: Aware vs. unaware Learners. Studies in Second Language Acquisition, 22(4), 557-584. http://dx.doi.org/10.1017/S0272263100004046

$\mathrm{Li}, \mathrm{S}$. (2012). The effects of input-based practice on pragmatic development of requests in L2 Chinese. Language Learning, 62, 403-438. http://dx.doi.org/10.1111/j.1467-9922.2011.00629.x

Lingli, D., \& Wannaruk, A. (2010). The effect of explicit and implicit instruction in English Refusals. Chinese Journal of Applied Linguistics, (33)3, 93-109.

Marbach-Ad, G., \& Sokolove, P. (2001). Creating direct channels of communication: Fostering interaction with e-mail and in-class notes. Journal of College Science Teaching, 31(3), 178-182.

Martin, M. M., Myers, S. A., \& Mottet, T. P. (1999). Students' motives for communicating with their instructors. Communication Education, 48, 157-164. http://dx.doi.org/10.1080/03634529909379163

Olshtain, E. (1989). Apologies across cultures. In S. Blum-Kulka, J. House, \& G. Kasper (Eds.), Cross-cultural pragmatics: requests and apologies. Norwood: N.J.: Albex.

Olshtain, E., \& Blum-Kulka, S. (1985). Degree of approximation: Nonnative reactions to native speech act behavior. In S. M. Gass \& C. Madsen (Eds.), Input in second language acquisition (pp. 303-325). New York: Newbury House.

Olshtain, E., \& Cohen, A. D. (1983). Apology: A speech act set. In N. Wolfson \& E. Judd (Eds.), Sociolinguistics 
Simin, S., Eslami, Z. R. ., Eslami-Rasekh, A., \& Ketabi, S.

and Language Acquisition. Rowley, MA: Newbury House Publishers.

Payne, C. (1997). Opening the door with e-mail: From no tech to low-tech. (ERIC Document Reproduction Service No. ED412936.) Retrieved April 3, 2007. From

http://leahi.kcc.hawaii.edu/org/tcc-conf/pres/payne.html

Poling, D. J. (1994). E-mail as an effective teaching supplement. Educational Technology, 34(5), 53-55.

Rose, K. R. (1994). On the validity of discourse completion tests in non-Western contexts. Applied Linguistics, 15, 1-14. http://dx.doi.org/10.1093/applin/15.1.1

Rose, K. R. (2005). On the effects of instruction in second language pragmatics. System, 33(3), 385-399. http://dx.doi.org/10.1016/j.system.2005.06.003

Schauer, G. A. (2006). Pragmatic awareness in ESL and EFL contexts: Contrast and development. Language Learning, 56(2), 269-318. http://dx.doi.org/10.1111/j.0023-8333.2006.00348.x

Schmidt, R. (1993). Consciousness, learning and interlanguage pragmatics. In G. Kasper \& S. Blum-Kulka (Eds.), Interlanguage pragmatics (pp. 21-42). Oxford: Oxford University Press.

Searle, J. R. (1969). Speech acts: An essay in the philosophy of language. Cambridge: Cambridge University Press. http://dx.doi.org/10.1017/CBO9781139173438

Takahashi, S. (2001). The role of input enhancement in developing pragmatic competence. In K. R. Rose \& G. Kasper (Eds.), Pragmatics in language teaching, (pp. 171-199). Cambridge: Cambridge University Press. http://dx.doi.org/10.1017/CBO9781139524797.014

Tateyama, Y., G. Kasper, L. Mui, H. Tay, \& Thananart, O. (1997). "Explicit and implicit teaching of pragmatic routines". In L. Bouton (Ed.), Pragmatics and Language Learning (vol. 8, pp. 163-178). Urbana IL: University of Illinois at Urbana-Champaign.

Yoshimi, D. R. (2001). Explicit instruction and JFL learner's use of interactional discourse markers. In K. R. Rose \& G. Kasper (Eds.), Pragmatics in Language Teaching (pp. 223-244). Cambridge: Cambridge University Press. http://dx.doi.org/10.1017/CBO9781139524797.016 